\title{
CONFLITO PELAS TERRAS E PELAS ÁGUAS: NOTAS DAS RELAÇÕES ENTRE MINERADORAS E PROPRIETÁRIOS RURAIS EM CORUMBÁ
}

\author{
EDGAR APARECIDO DA COSTA ${ }^{1}$ \\ Universidade Federal do Mato Grosso do Sul
}

\section{Reflexões iniciais}

Nos tempos atuais, marcados pela fluidez das informações, das mercadorias e da mão de obra (especializada ou não) impulsionadas pelo capital, os empreendimentos industriais se tornaram objeto de desejo de muitas unidades administrativas locais. São frequentemente relacionados ao desenvolvimento, decorrente da geração de empregos diretos e indiretos e da circulação de dinheiro que promovem nos centros urbanos. Entretanto, por detrás desses empreendimentos coexistem conflitos com populações tradicionais, com modos de vida orientados por outras lógicas.

Este estudo se propôs olhar para a manifestação desses conflitos na morraria do Urucum, no município de Corumbá, estado de Mato Grosso do Sul, próximo ao limite internacional com a Bolívia. Optou-se pela análise das relações dentro do polígono proposto desde 2006 para ser o polo minero-siderúrgico e gás químico de Corumbá. Trata-se de uma localidade conhecida como região de Maria Coelho, cuja denominação é motivada pela localização da estação ferroviária de Antônio Maria Coelho. É importante dizer que o termo região é, aqui, empregado em razão do tratamento popular e não como uma categoria geográfica.

As categorias de abordagem serão território e territorialidade. O território foi traduzido nessa reflexão sob inspiração de Souza (2000) e Saquet (2007), "[...] como um espaço delimitado por e a partir de relações de poder, cujas materialidades são reflexos das imaterialidades e das ações

1 edgarac10@gmail.com 
territoriais dos agentes e atores do espaço" (COSTA, 2009, p. 62). É delimitado, política ou culturalmente num espaço físico, contendo recursos naturais e materialmente construídos. São produzidos por agentes nem sempre exclusivos de um território e tampouco com territorialidades restritivas ao mesmo. O território é assim normatizado e produzido historicamente. Dessa forma, sob inspiração de Haesbaert e Limonad (2007), o território é um produto social, um constructo das relações de poder, que possui uma dimensão mais subjetiva, relacionada à apropriação e outra mais objetiva, ligada à dominação do espaço.

Entendeu-se que, em Maria Coelho, cada estabelecimento rural com fim de subsistência, de exploração comercial ou de turismo (para lazer) e cada empresa mineradora é um território. Vale notar que esses territórios estão contidos num território maior que abriga ainda outros, representado pelo município. Essa reflexão pode avançar para outras tantas escalas e motivações, mas não é o objeto desta análise. Buscou-se apontar que dentro de um território se configuram territórios em disputa por espaços submetidos pelas normas, mas confrontantes em interesses. Nessa perspectiva, em conformidade com Saquet (2007), o território é multiescalar e multitemporal. $\mathrm{Na}$ área de estudo foram vislumbrados tanto territórios que se orientam numa lógica multiescalar (SAQUET, 2007), ou seja, de maneira reticular, mas também territórios zonais, propostos por Haesbaert e Limonad (2007), de lógica contígua, local. No primeiro grupo, estão as empresas mineradoras: Vale, Grupo Vetorial e Grupo EBX; no segundo, estão os donos dos estabelecimentos rurais. Esses indivíduos/grupos construíram seus territórios em tempos diferentes e se confrontam na medida em que disputam mais espaço.

Assim, "[...] as territorialidades também são forjadas socialmente ao longo do tempo, em um processo de relativo enraizamento espacial" (HAESBAERT; LIMONAD, 2007, p. 47). A empresa mineradora Rio Tinto, quando adquiriu a Mineração Corumbaense Reunida (MCR), percebeu que a mesma gozava de boa aceitação na cidade. Sendo assim, não substituiu imediatamente a denominação anterior, somente o fazendo quando já estava, aparentemente, com raízes fixadas no território. Contudo, essas raízes não estavam suficientemente fincadas para suportar a crise do final de 2008, sendo sumariamente arrancadas e rearranjadas em outros territórios. Tanto que foi vendida para a Vale que ainda mantém, numa porção da área explorada, o nome MCR.

Deseja-se salientar que não foi intenção discutir teoricamente os conceitos de território e territorialidade. Pretendeu-se, sob esse manto, 
recuperar o sentido da "geografia de denúncias" prenunciada no limiar da chamada geografia crítica, mas relegada há algum tempo por outras causas.

Procurou-se descrever essas reflexões teóricas mediatizadas pela observação de campo em três eixos. Primeiramente uma apresentação histórica da ocupação das mineradoras na região de Maria Coelho, para, posterior e respectivamente, relatar os conflitos produzidos pela posse da terra e pelo uso das águas.

\section{Breve histórico da ocupação das minas de extração do ferro}

De acordo com Campos (1995), o conhecimento das jazidas de ferro e manganês do maciço do Urucum data de 1870, por ocasião do pedido feito pelo Barão de Vila Maria junto à corte imperial para concessão da exploração de ferro e manganês em sua propriedade. A outorga foi concedida em 1876 para os locais denominados Piraputanga e São Domingos (Decreto $\mathrm{n}^{\circ}$ 6.273, de 02/08/1876). Em 1880, foi emitida permissão para exploração da margem esquerda do rio Paraguai em favor de João Batista de Carvalho e Vasconcelos, Gustavo A. de Almeida Gama e Francisco Couto e Silva. Esse último conseguiu, em 1884, a concessão para exploração por 20 anos da morraria Urucum, realizando pesquisas sobre a qualidade e possibilidades das jazidas locais. Essas informações também são compartilhadas em Lamoso (2001), em sua tese de doutoramento.

Conforme Haralyi; Walde (1986), a Companhia do Urucum iniciou operação para retirada de ferro e manganês na porção sudoeste da morraria em 1906, contando com capital belga. Contudo, os reflexos internacionais da Primeira Guerra Mundial provocaram a paralisação na explotação desses minérios.

Na década de 1940, foram liberadas duas novas concessões na morraria do Urucum. Em 1940, a Sociedade Brasileira de Mineração, sob controle do Grupo Chamma - que, em parceria com a Cia Meridional de Mineração, subsidiária da empresa estadunidense U.S. Steel -, iniciou a exportação de minério de ferro através do rio Paraguai. Em 1944, a Sobramil passou a operar um pequeno forno com capacidade para a produção de 50 ton. de ferro-gusa ao dia, utilizando carvão vegetal como fonte de energia (HARALYI; WALDE, 1986). 
Portanto, o verdadeiro impulso da indústria mineradora em Corumbá ocorreu por volta dos anos 1940, ainda durante o período da Segunda Guerra Mundial, com a exploração das reservas de calcário, mesmo que de maneira insipiente, cuja repercussão foi capaz de atrair o grupo Itaú, em 1950 para explorar a produção de cimentos. Nessa mesma época, os trilhos da antiga Estrada de Ferro Noroeste do Brasil ${ }^{2}$ chegaram até a cidade de Corumbá, sendo considerado por muitos corumbaenses ${ }^{3}$ como um dos principais responsáveis pelo enfraquecimento da economia local e pela derrocada do comércio fluvial. Um dos argumentos que reforçam essa crença foi o fechamento do Moinho Mato-Grossense nos anos 1960, que utilizava trigo importado da Argentina, que chegava quando do retorno das embarcações que transportavam o minério extraído localmente.

A falência do transporte fluvial não é plenamente verdadeira, pois, ainda nos dias deste início de século XXI, as empresas mineradoras continuam utilizando os rios como principal meio de transporte para suas mercadorias. Logicamente não existem mais os grandes navios que chegavam a Corumbá no passado, pois a própria dinâmica do rio Paraguai orientada por múltiplos fatores impulsionou a necessidade de mudança do tipo de embarcação. As "chatas" se tornaram os tipos mais usuais, favorecidas pela capacidade de superar os trechos com baixa profundidade das águas.

Dentre os fatores que impeliram uma mudança da forma de escoamento da produção pelo rio Paraguai pode ser destacada a enorme quantidade de sedimentos trazidos pelos seus afluentes que são depositados em seu leito e na planície pantaneira. Os principais tributários desses materiais são os rios que formam a sub-bacia do Taquari a partir das práticas inadequadas das atividades agrícolas e da pecuária que permitem a

\footnotetext{
${ }^{2}$ Essa ferrovia foi privatizada em meados de 1990, sendo adquirida pela Ferrovia Novoeste S.A. e atualmente pertence à América Latina Logística S.A. A inauguração do eixo principal ocorreu em 1914, quando os trilhos foram completados, ligando o rio Paraná até as barrancas do rio Paraguai. Quase meio século depois, foram construídos os cerca de $100 \mathrm{~km}$ restantes até a cidade de Corumbá.

${ }^{3}$ Conversas informais e discussões nas aulas de "Gestão do território fronteiriço", do Programa de Mestrado em Estudos Fronteiriços, da Universidade Federal de Mato Grosso do Sul, campus de Pantanal.
} 
lixiviação do solo e o consequente o transporte para os rios ${ }^{4}$. Somam-se, ainda, como causas do assoreamento do Rio Paraguai as atividades garimpeiras no Estado de Mato Grosso - muito ativas até os anos 1970 -, a construção de estradas vicinais no planalto circundante ao Pantanal e a erosão em ambientes urbanos. Essa dinâmica de relacionamento sociedade/natureza no alto curso dos rios que formam a planície pantaneira impõe uma diminuição considerável na profundidade do rio Paraguai, sendo um fator limitante para alguns tipos de embarcações.

De acordo com Campos (1995), em 1972, foi criada a Companhia Matogrossense de Mineração - METAMAT para gerir os recursos minerais do estado de Mato Grosso. Em 1974, foi criada a Urucum Mineração S.A., devido à brecha deixada pelo fato de a Sobramil não ter solicitado a renovação do alvará de exploração mineral, contando com parceria da CRVD - Companhia Vale do Rio Doce (atualmente designada apenas por Vale). De 1976 até novembro de 1994, a CRVD (governo federal) detinha 46,66\% das ações da Urucum Mineração S.A., cujo controle era compartilhado em igual proporção ao governo estadual ${ }^{5}$ e apenas 6,68\% de participação da iniciativa privada, através da Convap que explorava a área do morro do Jacadigo. Entre novembro de 1994 e março de 1995, o governo federal, através da CVRD incorporou as ações dos governos estaduais de Mato Grosso e Mato Grosso do Sul, mantendo o percentual da iniciativa privada e a partir daí passou a controlar $100 \%$ das ações da Urucum Mineração S.A.

Campos (1995) aponta que, em 1974, também foi criada a Mineração Mato Grosso com foco na exportação de manganês para a Argentina e distribuição interna pela Companhia Paulista de Ferro-Ligas. No mesmo ano foi instituída a Mineração Doblados S.A., detendo concessões para exploração na Serra do Rabicho e no Morro Grande, além da Mineração Ocirema Ltda., com permissão para explotação de ferro e manganês também na Serra do Rabicho. Cabe ressaltar que essas denominações de

${ }^{4}$ Essas práticas foram constatadas pelo pesquisador durante os trabalhos para elaboração do Plano Diretor Participativo do município de Camapuã-MS, em 2005-2006.

${ }^{5}$ Até abril de 1994 a METAMAT detinha o controle dos $46,66 \%$ das ações. Com a divisão do estado, em 1977 e com as disputas para controle das ações das cotas estaduais de mineração no território sul-mato-grossense, de abril a novembro de 1994, o governo do novo estado conseguiu o controle de $18,66 \%$ das ações, ficando $28 \%$ com a METAMAT. 
serras e morros são locais e todas se referem a porções do complexo denominado Maciço de Urucum (Figura 1). A figura demonstra ainda a localização da estação de Maria Coelho em cuja proximidade está a área de conflito que será analisada mais adiante. Além disso, pode-se observar que a estrada de ferro corta, no sentido norte-sul, a extensão da morraria do Urucum, e se estende até a cidade de Corumbá, facilitando o acesso ao rio Paraguai e, portanto, o escoamento pela bacia do Prata.

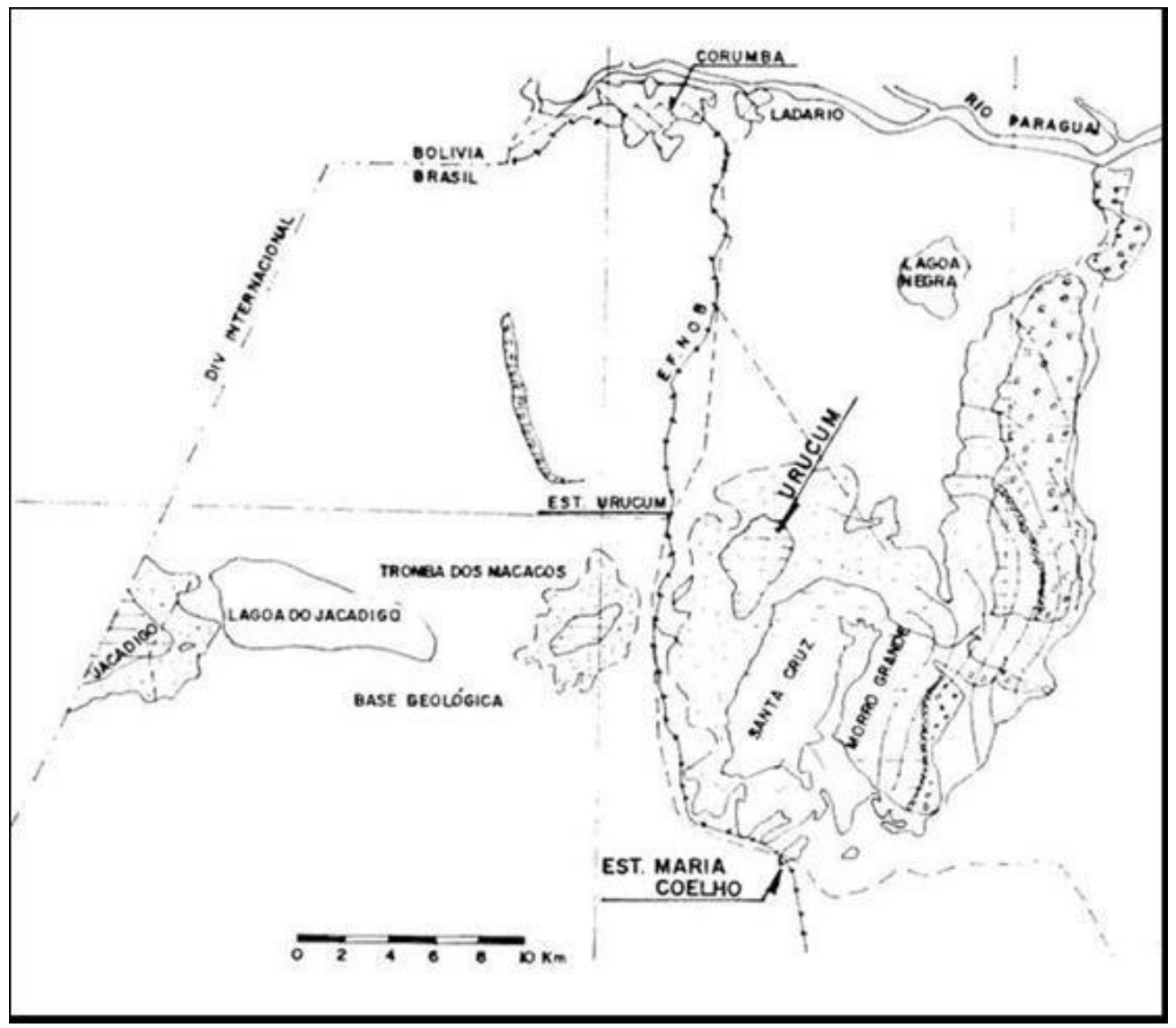

Figura 1. Esquema da localização do Maciço de Urucum, Mato Grosso do Sul. Fonte: Haralyi; Walde, 1986. 
Observa-se, também, a proximidade do limite internacional com a Bolívia e esse elemento faz dessa área um espaço localizado na faixa de fronteira (150 km a partir do limite, no Brasil). A Lei $\mathrm{N}^{\circ} 6.634$, de 2 de maio de 1979, que regulamentou a Faixa de Fronteira, alterando o Decretolei $\mathrm{N}^{\mathrm{o}} 1.135$, de 3 de dezembro de 1970, em seu Art. $2^{\circ}$, inciso IV, alínea "a" veda a instalação de empresas que se dedicarem a "pesquisa, lavra, exploração e aproveitamento de recursos minerais, salvo aqueles de imediata aplicação na construção civil, assim classificados no Código de Mineração" (BRASIL, 1979).

Essa faixa seria controlada pelo Conselho de Segurança Nacional ${ }^{6}$ (CSN) que foi extinto durante o governo Collor. Essa situação, aliada à vontade política estadual, possibilitou não somente a instalação da Rio Tinto, como também a doação de uma área com 2.123,13 ha, para estabelecimento de um polo minero-siderúrgico em Corumbá, na região de Maria Coelho (MOTA, 2009; LIMA, 2008).

De acordo com LIMA (2008, p. 11), até inicio de 2008 estavam instaladas as seguintes empresas de exploração de minério de ferro em Corumbá e Ladário, na morraria do Urucum:

\section{[...] Corumbá Mineração (COMIN), do Grupo Vetorial; a Urucum Mineração SA. (UMSA), da Cia Vale do Rio Doce (VALE); Mineração Corumbaense Reunida (MCR), pertencente à multinacional Rio Tinto do Brasil (RTB); Mineração e Metálicos do Brasil Ltda. (MMX), do Grupo EBX; Mineração Pirâmide Participações (MPP).}

Contudo, a crise mundial do final de 2008 e início de 2009 mudou esse panorama. A Rio Tinto do Brasil vendeu suas operações no Mato Grosso do Sul para a Vale e a MMX vendeu seu mais importante investimento - a MMX Metálicos (que envolve a siderurgia que já funciona na região) para o Grupo Vetorial, ficando apenas com a mina. Foi uma mudança drástica, inesperada, pois as empresas vinham projetando constantemente o aumento da exploração e/ou transformação mineral. Também, veiculava-se a possibilidade concreta da instalação do pólo minero-siderúrgico e de gás-químico na área concedida pelo estado, já tendo inclusive realizado Estudos de Impacto Ambiental (LIMA, 2008).

6 Durante os anos 1970 e 1980 ainda estava em vigor a terminologia CSN. A partir da Constituição Brasileira de 1988, o CSN converteu-se em CDN Conselho de Defesa Nacional. 
Nesse sentido, tanto a empresa estrangeira quanto a nacional adotaram os mesmos procedimentos: fechamento das portas para investimentos locais, comprovando que o capital é mesmo desterritorializado e sem valores topofílicos. Certificou-se também que nessa fase atual do meio técnico-científico-informacional aprofundaram a fluidez com a qual os investimentos se territorializam, desterritorializam e reterritorializam, promovendo verdadeiras incertezas nas populações locais.

Observa-se ainda uma continuidade das jazidas de ferro na Bolívia, no Maciço de Mutum que os bolivianos fronteiriços afirmam ser a maior jazida mundial desse minério. De acordo com Corrêa (2007), além das jazidas de manganês e ferro do Maciço de Urucum e do calcário, existe outra riqueza pouco conhecida no município de Corumbá, que representa considerável valor estratégico para a segurança nacional. Trata-se de uma imensa reserva de calcita ótica, de rara ocorrência no mundo, utilizada na confecção de lentes de alta precisão para a mira de armamentos e de raio laser. Não existe, contudo, informação sobre essa exploração e sua presença é tratada como reserva de mercado.

Quanto às empresas mineradoras instaladas, cabe observar o variado grau de impacto que elas provocam e provocaram em Corumbá. É significativamente visível que elas trouxeram, para a cidade, vários profissionais de outros estados, pois não havia mão de obra qualificada disponível no local para suas necessidades. Os relacionamentos daí advindos produziram trocas de técnicas e culturas que podem impulsionar novos ânimos para a localidade. A geração e oferta de empregos também são inegáveis, seja direta ou indiretamente. Por outro lado, a convivência com a população de entorno nem sempre foi de favorecimentos. São essas as questões motivadoras das páginas seguintes, vislumbradas em duas perspectivas: quanto à posse da terra e quanto ao uso da água.

\section{O conflito pela terra com as mineradoras em Maria Coelho, Corumbá-MS}

A estação de Antonio Maria Coelho, mais conhecida localmente pelos dois últimos nomes (Maria Coelho), foi inaugurada em 1952, localizada entre as estações de Carandazal e de Corumbá. Atualmente é administrada pela ferrovia Novoeste, da ALL - America Latina Logística e se localiza a cerca de $40 \mathrm{~km}$ ao sul da cidade de Corumbá, 
[...] estrategicamente em relação às principais lavras de minério de ferro, contém os pátios de estocagem e transbordo de minérios, inserindo-se na área do futuro Pólo Siderúrgico, razão pela qual tem sido, sistematicamente, tomada como referência nos diversos projetos minero-metalúrgicos (LIMA, 2008, p. 22).

A região apresenta uma grande densidade de atividades mineradoras, além da área destinada ao polo minero-siderúrgico. Essas atividades se misturam num espaço organizado entre pequenos e grandes estabelecimentos rurais de uso agropecuário ou com finalidade de exploração do turismo; entre os interesses de uso produtivo e de consumo mediado pelo lazer. Além disso, existe um enclave de 1.300 hectares representado pelo Parque Natural Piraputangas, que é uma Unidade de Conservação Municipal criada em maio de 2003 sob a guarda da Rio Tinto e atualmente da Vale.

Para se compreender a configuração real do uso e da posse das terras na região de Maria Coelho foi preciso indagar os proprietários sobre seus relacionamentos com as mineradoras. O trabalho de campo ocorreu em dois momentos, a fim de comparar a evolução das questões: o primeiro, no início de 2007 e o segundo, no final de 2009. Inicialmente se tinha uma ideia de que as mineradoras representavam oportunidade de trabalho, ou seja, muitos, senão a maioria, seriam empregados por elas. Em relação aos impactos ambientais, várias pessoas afirmavam que o uso da água pelas mineradoras estaria comprometendo os pequenos cursos fluviais e causando dificuldades de abastecimento dos moradores locais. A opção de universo de pesquisa foi pela parte interna dos vértices da área do polo minero-siderúrgico. Nesse caso foi estabelecida a investigação de todos os estabelecimentos que estivessem nessa localidade e que poderiam ser alvo - se mantidas as dimensões e localização do pólo - de possíveis desapropriações.

A fim de identificar as residências, foi utilizado o Google Earth posicionado sobre a área de pesquisa. Assim, foi possível localizar e realizar o apontamento das mesmas num croqui. Em seguida, foi feito o trabalho de campo, utilizando um roteiro de entrevistas e máquina fotográfica para registro de detalhes significativos para análise. Utilizamos um GPS marca eTrex Vista HCx da Garmin a fim de assegurar se a localização do estabelecimento estava mesmo na área core do polo. As questões colocadas aos proprietários versaram sobre educação, saúde, lazer, comercialização, produção para consumo, segurança pública, 
problemas enfrentados pela comunidade local, potencialidades locais, principais aspirações pessoais e coletivas, tempo de moradia, sentimento topofílico, se conheciam o projeto de implantação do polo minerosiderúrgico e, por último, o que fariam se tivessem que ser desapropriados.

Utilizou-se ainda da técnica da observação focada na atenção das materialidades construídas, como tipo das casas, condição das estradas, desvios de cursos d'água etc.

Em 2007, foram levantados 12 estabelecimentos agropecuários cujos tamanhos variavam significativamente (menos de um a quase mil hectares), sendo que desses, 3 já tinham sido comprados por uma empresa mineradora, mas os antigos donos continuavam no local. Visitaram-se, ainda, os quatro balneários e uma comunidade que também estão dentro da área destinada ao polo. Além disso, foram entrevistadas as lideranças dos assentamentos que ficam no entorno geográfico imediato da área destinada ao polo, quais sejam: os assentamentos rurais Mato Grande e São Gabriel. Em 2009, foram visitados um balneário, a comunidade da Igrejinha e um proprietário remanescente das "desapropriações" e observada toda a área interior do polo.

Em relação à presença institucional, em Maria Coelho, funciona a Escola Municipal Castro Alves que trabalha de forma multisseriada (as aulas são juntas) no período matutino, atendendo do $1^{\circ}$ ao $5^{\circ}$ ano do ensino fundamental. Trata-se de uma extensão da Escola Municipal Carlos Carcano, que é um Polo Educacional localizado no Assentamento Urucum, situado a cerca de $20 \mathrm{~km}$ do local. Os demais alunos do ensino fundamental vão para esse Polo por meio de ônibus escolar e os do ensino médio vão para uma Escola Estadual localizada no distrito de Albuquerque, nas mesmas condições de deslocamento.

Em relação à oferta de serviços de saúde, existe um prédio (construído pela Rio Tinto) no qual funciona às quartas-feiras (no intervalo de 15 dias) o atendimento que foi categorizado como insuficiente, em termos de especialidades médicas, pelos entrevistados. Para seu funcionamento, a Prefeitura fornece o transporte dos profissionais e, em casos de assistência médica emergencial, as pessoas são deslocadas para a sede. Registrou-se, nas entrevistas, que várias situações de urgência, em relação ao transporte, foram atendidas por parte das mineradoras especialmente da MMX e da MCR (Rio Tinto, atual Vale). A região não conta com posto policial, corpo de bombeiros nem outro prédio 
institucional, sendo, no entanto, servida por rede de energia e de telefonia rural.

Nesse contexto, estão as intencionalidades e são desenhadas as várias territorialidades. A forma de utilização das terras é diferenciada entre os estabelecimentos de maior e os de menor porte, sendo que no primeiro grupo predomina a atividade pecuária, marcada pela presença relativa de pastagens plantadas, enquanto que no segundo, as lavouras de subsistências são mais marcantes. Não se adotará a classificação de propriedades do INCRA: pequenas, médias e grandes e se utilizará a denominação de estabelecimento (lembrando o IBGE) e não, a de propriedade, em razão das condições que serão demonstradas ao longo das descrições e análises seguintes. Optou-se, pelas características locais, chamar de pequenos e maiores estabelecimentos rurais cuja motivação está no tamanho e no uso do espaço.

\section{Os pequenos estabelecimentos rurais}

Em 2007, foram identificados nove pequenos estabelecimentos rurais, mas pelo teor das entrevistas acredita-se que existiam mais cinco que já haviam sido comprados por uma das mineradoras. Foram agrupados nesta categoria, estabelecimentos com áreas entre menos de 1 até 49 hectares, com predominância na faixa de 5 a 15 hectares. Vale observar que todos possuem posse de terra com mais de 10 anos e elevado sentimento topofílico.

Ao que tudo indica, a posse das pequenas áreas territoriais em Maria Coelho teve origem nas terras de uma antiga proprietária. Segundo relatos, a propriedade original foi herdada em 1969, com 7 ha. Pelo que se pôde apurar nas entrevistas, tratava-se de uma área que pertencera ao grupo Chamma que, ao final de suas atividades na estação de Maria Coelho, cedeu 1,5 ha na forma de compensação (que a proprietária chamou de herança). Mais tarde, quando esse grupo já não operava mais na região, durante a tentativa de regularização fundiária, verificou-se que existiam áreas devolutas, sendo ampliada, por volta de 1985, para 25 ha. Outra possibilidade a ser considerada era de as terras devolutas serem resultantes da antiga concessão feita ao Barão de Vila Maria para exploração mineral, na segunda metade do século XIX. Suspeita-se que a ocupação de terras foi ainda maior, pois vários proprietários próximos informaram que 
adquiriram suas áreas junto àquela antiga proprietária e o somatório dessas é maior que os 25 hectares mencionados.

Essa questão se confirmou em outra direção. Uma das empresas mineradoras, fortemente interessada na expulsão dos proprietários rurais da região começou a fazer ofertas de compra das terras. Mediante a resistência dos mesmos, o departamento jurídico da mineradora entrou em ação, levantando informações sobre a titularidade. Descobriu-se que existia um termo de compra, mas não, a escrituração da mesma. A antiga proprietária havia vendido várias partes de suas terras, mas fora impedida juridicamente de regulamentar em função da complicada condição de título de propriedade.

Foram esses argumentos que o referido departamento jurídico utilizou para pressionar a saída dos pequenos proprietários rurais, transformados em posseiros. O agravante contrário aos sitiantes (ou pequenos chacareiros) era a posse de propriedade em área urbana, impossibilitando o requerimento de usucapião. Dessa forma muitos cederam às pressões dos advogados da empresa e aceitaram uma "indenização" equivalente a 80 mil reais (em torno de 43 mil dólares, na época). Materializaram-se, assim, duas formas de territorialidades individuais: a da mineradora, partindo do conhecimento do território com estratégias de ampliação de área, e a dos produtores rurais, com forte vínculo territorial e estratégias de resistência.

Em acordo com os relatos de todos os posseiros, as táticas empregadas eram de ameaça de perda da terra sem qualquer indenização e até mesmo de ter que responder à justiça pela posse irregular de áreas. A pressão funcionou, pois se constatou em 2007, a venda de 3 e de outros 5 anteriores à pesquisa de campo. Além disso, outros 4 estavam fortemente inclinados a aceitar a proposta da mineradora e na pesquisa de campo de 2009 , isso se confirmou.

Dos estabelecimentos que já estavam vendidos, dois funcionavam como bar e restaurante e o outro era aquele que deu origem à maioria dos pequenos estabelecimentos locais. Nesse último, funcionava uma agricultura familiar, com produção de feijão, mandioca, banana, milho, melancia, manga e abóbora, sendo parte destinada ao consumo próprio e outra parte, à venda. Em conversa com o esposo da proprietária foi possível apurar que a empresa mineradora impôs sua territorialidade fortemente na região. A pressão foi orientada pelo questionamento da legalidade dos títulos de posse e o medo de perder tudo e dos transtornos 
com o judiciário motivou a venda. Note-se que, nesse caso, tratou-se de uma compra estratégica, pois o estabelecimento era a matriz de muitos outros que não foram desmembrados legalmente, havendo apenas declaração de compra e venda, sem título. Especula-se que esse fato possa ter levado a empresa a "indenizar" uma quantia bem maior que a oferecida aos demais, pois demonstrando a fragilidade documentária da posse original desmontaria, em muito, a resistência das posses derivadas da mesma.

Os estabelecimentos que funcionavam como bar e restaurante (Figura 2) tinham como clientes os trabalhadores da mineração, especialmente os caminhoneiros do transporte de minério ou dos caminhões pipas, destinados a molhar a estrada para fins de impedir poeira. Ambos afirmaram que não desejavam vender, pois possuíam uma boa renda mensal, variável entre 5 e 6 mil reais (valor bruto). Segundo informações obtidas, a terra comprada tinha problema com regularização fundiária e, por isso, aceitaram vender. Possuíam casas de alvenaria demonstrando bom estado de conservação, mas algumas benfeitorias já mostravam sinais de abandono. Num deles, havia campo de futebol e área de pomar e no outro, piscina, plantação de limão em escala comercial e produção de feijão, milho e mandioca, além de hortifrutigranjeiros para subsistência.

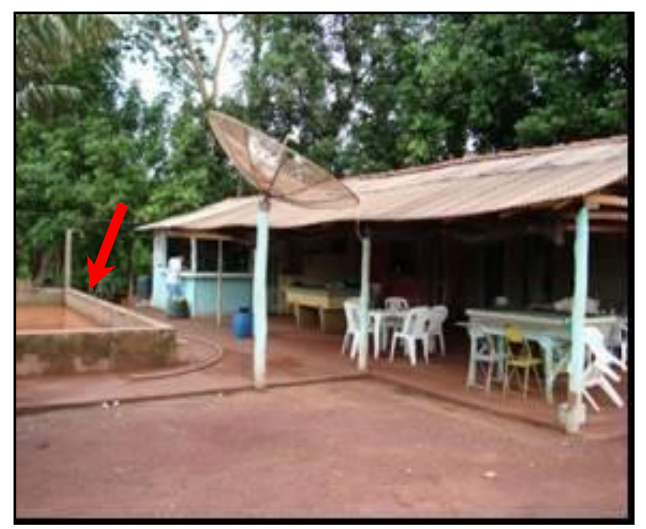

Figura 2. Bar e restaurante em 2007 Autor: Costa, E.A., 2007.

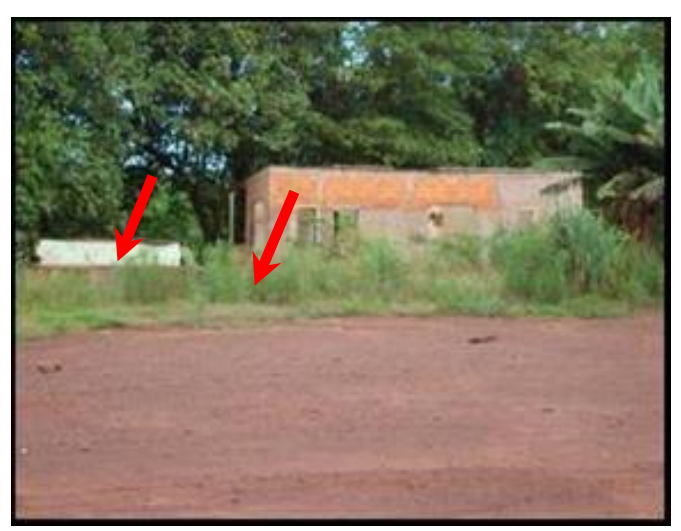

Figura 3. Bar e restaurante em 2009 Autor: Costa, E.A., 2009.

A estrutura observada pela seta, na parte esquerda da figura 2 , é a de uma piscina abandonada, com uma mistura de água e lama, demonstrando 
sinais do abandono. Em 2009, os antigos donos já haviam sido expulsos, levando a maior parte das telhas e das madeiras utilizadas (Figura 3). O estado de abandono era completo, restando da piscina apenas a estrutura de concreto, indicada pela seta.

Sobre os demais pequenos estabelecimentos, vale destacar o situado ao longo da BR 262, comprado em 1990 com 49 ha, pertencente a uma família boliviana, caracterizando-se como agricultura familiar. Apresentava uma sede muito boa, salão de festas, cozinha em separado, galpão de guarda dos maquinários, casa de caseiro, curral da leiteria todo cimentado, galinheiro, galpão destinado aos veículos, curral para os carneiros e campo de futebol. A pecuária era a principal atividade, destacando-se 60 cabeças de vacas leiteiras e 50 carneiros. A proprietária afirmou conviver bem com as mineradoras, especialmente com a MMX que possui um medidor de emissões de poluição atmosférica instalado no local.

Outro destaque observado foi um estabelecimento com 2 ha, onde antigamente funcionava a escola local e que passou a ser uma espécie de retiro religioso de evangélicos. Ficava ao lado da estação ferroviária de Antonio Maria Coelho com várias construções que serviam como alojamento principalmente durante as festividades como carnaval e outros feriados nos quais a comunidade evangélica ia para retiro espiritual. Possuía ainda amplo salão de festas, uma piscina desativada, um campo de futebol e, aos fundos, um córrego que atravessa os balneários da região, denominado de Piraputangas. Não apresentava atividades agrícolas ou pecuárias, mas possuía suas marcas nas margens do córrego já descaracterizadas de sua paisagem original (mata tropical), vislumbrando pastagens plantadas. Em 2009, essa propriedade já fora vendida para uma das empresas mineradoras.

O estabelecimento com menos de um hectare possuía uma casa de alvenaria como moradia e um salão onde funcionava a lanchonete e a borracharia. Durante a entrevista, em 2007, percebeu-se que o mesmo estava tentando um financiando para construção de: quartos de aluguel a fim de atender os caminhoneiros que trabalhavam na região, um prédio novo para a lanchonete, além de equipamentos modernos para atender a demanda das novas tecnologias de pneus para caminhões. Em 2009, pela observação da paisagem, a borracharia já estava fechada e os sonhos do agora ex-proprietário (conforme informações orais) não foram concretizados. 
Nos demais estabelecimentos, destacavam-se as produções de subsistência como limão, banana, berinjela, alface, couve, pimentão, cheiro verde, agrião, dentre outros, em uma delas, e cultivo de mandioca, abóbora, melancia, em outra.

Dentre os pequenos estabelecimentos que receberam proposta diferenciada de "indenização", foi observado apenas um. Tratava-se de uma área adquirida por meio de compra em 1992 e com posse de quase 60 anos. Eram 25 ha registrados, mas com ocupação entre 29 e 30 ha. No que tange às edificações, verificou-se a existência de uma casa da sede e um curral. Eram criados 75 bovinos, 20 galinhas e dois cavalos. A principal atividade era a bovinocultura leiteira, usando também a engorda e a venda de cabeças. A utilização de mão de obra era familiar, sendo que dentre as técnicas empregadas foram citadas a vacinação, o combate a parasitas, a divisão de pastagens e separação por sexo. A produção agrícola era de milho, feijão e mandioca destinada ao consumo familiar e para ração animal. Afirmou que estava negociando a venda por 200 mil reais para a MMX, mas que desejava um valor maior. Em 2009 já não estava mais no local.

\section{Os maiores estabelecimentos rurais}

Foram encontrados três maiores estabelecimentos localizados na área do polo, sendo seus proprietários também agentes de outras atividades urbanas. Ao contrário da maioria dos pequenos, todos possuem título de propriedade, sendo 990 ha, 520 ha e 178 ha, respectivamente. A maior propriedade foi adquirida em 1998 onde vivem duas famílias, cujas principais edificações correspondem a casa sede, 2 casas de empregados, 2 depósitos de materiais, uma salgadeira, 1 curral, 1 brete e uma balança. A principal atividade é a bovinocultura de corte, possuindo um efetivo de gado nelore de alta linhagem com cerca de 200 cabeças. Utiliza práticas de manejo do gado intensivas em tecnologia, como: combate a parasitas, divisão de pastagens, separação por sexo, programação de cruzamento, inseminação artificial, suplementação alimentar na seca (rações balanceadas para o gado de elite), entre outras. A produção agrícola é de mandioca, milho, abóbora e melancia e se destina ao consumo das famílias residentes e para ração animal. $\mathrm{O}$ estabelecimento conta também com um pomar irrigado com a técnica de gotejamento, com mais de mil mudas, além de infraestrutura para lazer. Sua área é tocada parcialmente pelos vértices do polo e possui $80 \%$ da área em mata nativa preservada. 
O estabelecimento com tamanho intermediário foi comprado em 1996. Dentre as instalações, destaca-se a casa da sede, 2 casas de empregados, curral coberto de alvenaria, brete coberto, casa de carneiros, cocheira para cavalos, cocheira para gado bovino de linhagem pura, garagem para maquinário e caminhão e galpão. Possui rebanho de 712 bovinos, 60 carneiros e 46 cavalos. A principal atividade é a bovinocultura de corte, utilizando as mesmas técnicas de manejo descritas anteriormente. As fontes básicas de abastecimento de água são os piletes de concreto (a água é levada através de encanamento) e de cinco córregos que atravessam a propriedade (dois perenes e três que só escoam na estação chuvosa).

$\mathrm{O}$ menor dentre os grandes estabelecimentos identificados tem como atividade principal a criação de cavalos de raça, funcionando como um haras. São criados cavalos de linhagem pura, contando com reprodutores para venda de sêmen e de potros produzidos localmente para exposições e venda em leilões (Figura 4). Conta com uma sede com boas instalações, casa do capataz, galpão para dormitório dos peões e vários outros utilizados como depósito, garagem para os maquinários, currais para bovinos e ovinos, chiqueiro para os porcos e javali. Produz a cruza de suínos com javali e possui ainda um plantel de bovinos de alta qualidade, melhorados geneticamente para a produção leiteira. Em grande parte do ano de 2007, contou com a contratação de 18 trabalhadores diaristas que atuaram na plantação da grama Tifton 85 (Figura 5). Essa gramínea foi plantada através de mudas trazidas do estado de São Paulo e possui elevado preço agregado. Cerca de 10 ha foram preparados para receber a grama demandando o aterramento com mais de 20 mil caminhões de terra, além de fertilizantes para adubação do solo.
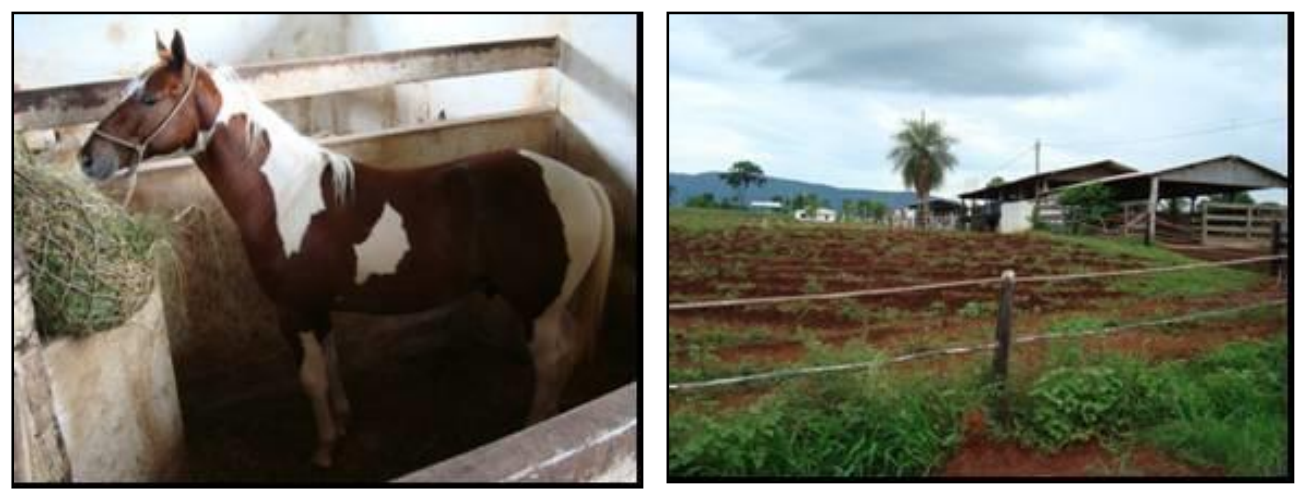

Figura 4. Potro premiado Autor: Costa, E.A., 2007
Figura 5. Plantação de Tifton 85

Autor: Costa, E.A., 2007 
A propriedade, localizada às margens da BR 262, depende dos cursos d'água cujas nascentes estão na área comprada pela Vale. A diminuição desse recurso compromete seriamente o rebanho que dele depende, sendo essa a maior preocupação quanto a elas. Trata-se de um produtor que investe em alta tecnologia para melhoramento do seu plantel, pois disso depende para competições. O investimento nesse tipo de gramínea (Tifton 85) deve-se ao fato de ela ser muito rica em nutrientes, chegando a dispensar o uso de ração ou servir como tal.

Portanto, o conflito pela terra entre as mineradoras e os maiores estabelecimentos de Maria Coelho se dá em função da área de localização do polo que atingiria seus limites. São membros de famílias tradicionais com grande influência política. Um deles já foi presidente da Associação Comercial de Corumbá e do Corumbaense Futebol Clube, portanto, bastante influente na cidade. Além disso, os investimentos realizados pelos produtores denunciam a opção em não desejar a venda de suas terras. Observa-se, pois, um choque de territorialidades que convergem para um mesmo espaço tornado ou a ser tornado território a partir de interesses distintos, que tensionam as relações locais.

\section{Os balneários}

Foram identificados quatro balneários: Menck, Lago Azul, Iracema e o do Mesquita. São empreendimentos particulares direcionados ao turismo de lazer na região, frequentados pela população moradora dos municípios de Corumbá e Ladário durante os fins de semana e o período de férias escolares, além dos povos bolivianos da região fronteiriça (Puerto Quijarro e Puerto Suárez). O principal atrativo desses balneários são as piscinas ou lagos de águas naturais construídas através de pequenas barragens, as quadras esportivas, quiosques e churrasqueiras, além do contato com a natureza.

O Balneário lago Azul é um clube particular com 2 ha e toda a estrutura de um clube de lazer, como quadras, campo de futebol, piscina de água natural e escorregador, bar, vestiários, quiosques, playground, sede administrativa, entre outras benfeitorias. Recebe em torno de mil habitantes por final de semana, considerando que no período de inverno (junho-julho) essa quantidade é bem menor, pois as águas ficam bem frias. Nos dias mais quentes é possível registrar um número de visitas ainda maior. 
O Balneário Menck também é particular, com 2 ha e infraestrutura de lazer como piscinas naturais, 20 quiosques com churrasqueiras, bar, 2 quadras esportivas, 1 campo de futebol, sede administrativa construída em dois pavimentos com salão de festas e capacidade para 150 a 200 visitantes. Recebe a mesma quantidade de visitantes semanais que o anterior. Os proprietários de ambos têm em comum o fato de serem empresários no ramo do comércio na cidade de Corumbá.

Já o Balneário Iracema é uma propriedade particular que possui boa infraestrutura de lazer, como piscina natural, escorregador na piscina, quiosques com churrasqueiras, sede administrativa, campos de futebol, bar etc. e que recebe em média de 400 a 500 visitantes por final de semana. Trata-se de uma área com 113 ha, adquirida por meio de compra desde 1960 e que foi vendida recentemente a uma família boliviana. Além das atividades ligadas ao lazer, possui lavoura de mandioca e alface, para venda, e abóbora, feijão e milho, para consumo.

O outro balneário localiza-se na propriedade de Rômulo Mesquita que foi adquirida em 1995 e possui 2 ha. Ali reside uma família de 2 pessoas, com uma casa principal, uma casa alugada para um proprietário de caminhões-pipa que trabalha na região atendendo às mineradoras, campo de futebol, 2 quartos para aluguel nos finais de semana, garagem, galpão, pomar, galinheiro concretado, uma piscina e um bar e restaurante. Planta ainda feijão, mandioca, banana, milho e abóbora para consumo próprio. $\mathrm{O}$ córrego que passa pela propriedade apresenta bom estado de conservação das margens e é aproveitado pelos banhistas. $\mathrm{O}$ proprietário afirma que se sente pressionado para vender, mas admite não ter intenção de sair do local. Por outro lado, os valores oferecidos são equiparados aos de outras propriedades com menos benfeitorias que a dele. Alega, ainda, que seu local fica distante da usina siderúrgica e das minas, portanto sua presença não atrapalha as mineradoras.

Durante as entrevistas, constatou-se que nos balneários não foram registrados indicativos de violência, tampouco de roubo. Contam com a presença de salva-vidas nos finais de semana, quando são mais procurados, pois durante a semana permanecem em manutenção. Estão afastados a cerca de $45 \mathrm{~km}$ das cidades de Corumbá e Ladário. Não existe posto policial, de bombeiros ou da Defesa Civil nas proximidades, que se localizam na cidade de Corumbá. À exceção do Mesquita, os demais possuem caseiro e família, trabalhando e residindo no local. 


\section{As comunidades}

Quanto à presença de comunidades, observou-se essa situação sob dois aspectos: dentro da área nuclear de implantação do polo siderúrgico e no entorno do mesmo. Dentro da área destinada ao polo, existe uma comunidade evangélica que se autodenomina "Recanto dos Evangélicos", sendo mais conhecida regionalmente como comunidade da igrejinha. Trata-se de uma área coletiva com 25 ha e que nela residem 18 famílias com cerca de 80 pessoas.

A principal atividade de lazer está relacionada com a igreja evangélica local. As crianças estudam até o $5^{\circ}$ ano do ensino fundamental na escola da região de Maria Coelho e as demais se deslocam para a escola polo, situada no Assentamento Urucum ou vão para o distrito Albuquerque, ambas em torno de $20 \mathrm{~km}$ de distância. As compras são feitas na cidade de Corumbá, basicamente uma vez a cada mês. Afirmam jamais ter registrado casos de violência ou de roubo, sendo que as emergências médicas são socorridas pelas mineradoras.

Estão nessa localidade há quase 100 anos e não se sentem incomodados pela presença das mineradoras, apontando que a principal dificuldade estava em relação à água, já que o córrego que fluía por ali secou em 1995. O abastecimento durante muito tempo foi realizado por um fazendeiro vizinho e depois passou a ocorrer por meio de caminhões-pipa disponibilizados pelas mineradoras locais. Nota-se uma contradição, pois responsabilizam as mineradoras pelo córrego ter secado e a Associação dos Moradores de Maria Coelho foi criada com o propósito de resistência.

Cultivam apenas para a subsistência, pois a maioria possui um ou dois aposentados na família. Os principais cultivos são: milho, feijão e mandioca. Os mais jovens trabalham nas mineradoras locais. $\mathrm{O}$ território deles é organizado em forma de hábitat semiconcentrado, sendo uma casa para cada família, de diversos aspectos visuais, em conformidade com o gosto e poder aquisitivo de cada uma delas. A igreja representa o fortalecimento das relações, o lazer e o compromisso espiritual.

$\mathrm{O}$ assentamento Mato Grande fica a menos de $10 \mathrm{~km}$ do polo siderúrgico e compõe uma comunidade de entorno constituída por 50 parceleiros, com propriedades variando entre 14 e 29 ha. A maior parte trabalha com agricultura de subsistência $\mathrm{e}$ as principais culturas identificadas foram a mandioca, o feijão, o milho (Figura 6) e a banana. O arroz ainda é cultivado, porém em pequena escala. Também se destaca a 
atividade pecuária bovina (para corte e leite). O Assentamento conta com um posto de saúde, uma escola (ensino fundamental), uma unidade ambulatorial odontológica móvel do Projeto Sorria, patrocinado pela Vetorial. Além disso, possui 2 campos de futebol e espaço para reuniões e festas. É o local em que a maioria se desloca para atividades de lazer. Os alunos do ensino médio precisam se deslocar diariamente para o distrito Albuquerque e utilizam ônibus escolar oferecido pela prefeitura municipal.

Existe uma associação dos parceleiros do assentamento que administra o centro social. De acordo com seu presidente, a grande virtude do local é a fertilidade natural dos solos e os maiores problemas estão relacionados à conservação e manutenção das estradas. Outra potencialidade é a presença de uma imensa baía (Figura 7) nas proximidades do Centro Comunitário. Gostam de morar no local e, para enfrentar suas principais dificuldades, buscam apoio na EMBRAPA Pantanal - Empresa Brasileira de Pesquisa Agropecuária e a AGRAER-MS - Agência de Desenvolvimento Agrário e Extensão Rural.

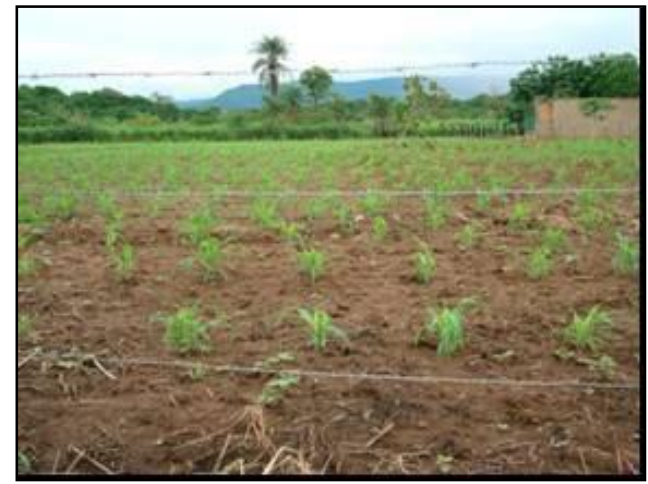

Figura 6. Plantação de milho Autor: Costa, E.A., 2007

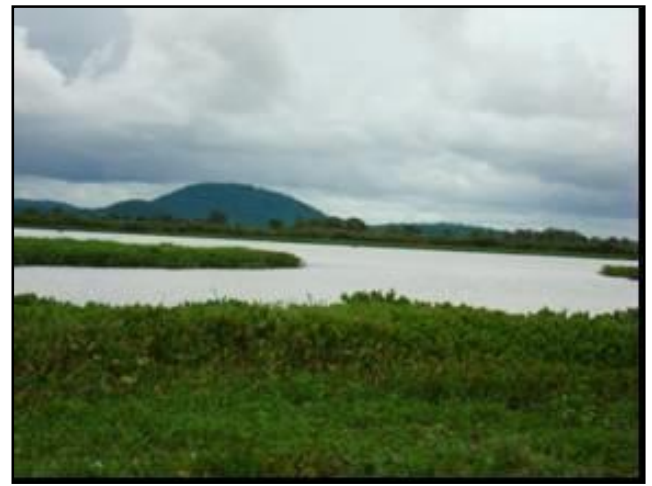

Figura 7. Baía Autor: Costa, E.A., 2007

Embora a associação de parceleiros tenha trator e alguns equipamentos agrícolas comunitários, muitas vezes, a plantação é quase rudimentar, com a utilização de matracas. A exploração do turismo rural é somente uma potencialidade que poderá ser reforçada pela possibilidade de atrelar essa atividade com a imensa baía que margeia o sudeste do assentamento. É rica em recursos pesqueiros, tem um belo visual, mas sua água não pode ser aproveitada para irrigação ou consumo, pelo fato de ser 
salobra e não disporem de técnicas para a retirada do excesso de sal nela contida.

Não existe posto policial no local, tampouco unidade de corpo de bombeiros e da defesa civil nas redondezas. Contudo, apurou-se a existência de apenas um caso de roubo em duas propriedades. Segundo os relatos, a Polícia exigia o pagamento do combustível para o deslocamento de Corumbá, tornando impraticáveis as ações de busca e apreensão. No geral, as festas são sempre amistosas e sem confusão.

O assentamento rural São Gabriel é outra comunidade de entorno, estando a menos de $10 \mathrm{~km}$ dos vértices sul do polo siderúrgico. É formado por 292 lotes, dividido em 5 Associações de moradores registradas, duas com 59 famílias e outras três, com 58 famílias. Funciona na forma de regime socioproprietário no qual o parceleiro recebe um lote individual, no caso de 4 ha e mais o equivalente a 7 ha, no coletivo. Trata-se de um assentamento recente, criado em 2006 e que, por isso, muitas casas ainda apresentam aspectos precários. A maioria é feita de taipa e de madeira. Cultivam vários produtos de subsistência no lote individual e estão preparando projetos de leiteria e outras lavouras comerciais no coletivo. Contudo, ainda é um sistema em aprendizado. A terra apresenta boa fertilidade natural, mas carecem de água e energia - que foi rebaixada em 2008. A água existe, mas é salobra - desagradável para consumo humano e dos animais de criação.

Os deslocamentos se dão por ocasião das compras, da busca por serviços de saúde e para estudo. Os alunos estudam até o $5^{\circ}$ ano do ensino fundamental numa escola localizada na sede da antiga fazenda e atual centro comunitário. Os demais se deslocam para a unidade escolar polo, localizada no assentamento Urucum e para o distrito Albuquerque, ambos a cerca de $30 \mathrm{~km}$.

Os assentados veem o polo siderúrgico como oportunidade de trabalho e como parceiro já que por diversas vezes receberam apoio das mineradoras. Em situação de dificuldades, quase sempre recorrem ao representante do INCRA que cuida do assentamento. Não existem postos policiais, de corpo de bombeiros ou da defesa civil. Contudo, afirmam jamais ter registrado casos de violência ou de roubo.

$\mathrm{Na}$ área considerada pelo estudo como entorno do Polo Siderúrgico, foi identificada ainda a presença de um cemitério datado do século XIX, cujo valor histórico é reconhecido pela população e por estudiosos que frequentemente visitam o local. 


\section{O conflito pelas águas com as mineradoras em Maria Coelho, Corumbá-MS}

Além do conflito pelas terras foi registrada, também, uma disputa pelo uso da água em Maria Coelho. Essa tensão nas relações ocorre entre todos os agentes da produção territorial: donos dos pequenos estabelecimentos rurais, dos maiores estabelecimentos, dos balneários e da comunidade da igrejinha, contra o uso das mineradoras.

As mineradoras dependem da água para suas atividades, assim como os balneários para encher suas piscinas. As mineradoras precisam da água, especialmente na fase da separação, posterior à britagem, quando é utilizada no peneiramento através de jatos que ajudam a separar o minério dos restos de terra, alem de vários outros processos. A água é reutilizada, devendo ser devolvida em estado semelhante ao da origem antes de voltar ao leito natural. Também utilizam água para molhar permanentemente as estradas, evitando poeiras e, nesse sentido, começa o ponto de discórdia com os proprietários de balneários.

Os balneários locais foram construídos aproveitando-se da declividade natural, realizando um represamento ao longo do córrego Piraputangas ou construindo um canal a fim de desviar as águas para um reservatório (piscina), que retornam ao curso através de uma espécie de sangradouro (abertura que permite a saída do excedente para encher a piscina). As águas oriundas das nascentes, na morraria local, são relativamente frias em comparação às elevadas temperaturas registradas de agosto a maio em Corumbá e Ladário e nas cidades fronteiriças bolivianas de Puerto Quijarro e Puerto Suárez $\left(35\right.$ a $\left.42^{\circ} \mathrm{C}\right)$. Sendo assim, os balneários são um atrativo de lazer para parte das classes médias e alta dessas localidades.

Durante as entrevistas, foram observadas várias menções sobre a diminuição das águas e mesmo da mudança de capacidade perene de alguns pequenos cursos fluviais. Não era objetivo, deste estudo, verificar cientificamente essa redução, pois isso exigiria alguma escala temporal de observação e medição sistemáticas. Contudo, os informes locais servem para ativar suspeitas desse processo de diminuição da oferta natural de água superficial.

Outro aspecto que apareceu nas conversas, especialmente com o pessoal do balneário Lago Azul, era que os caminhoneiros desviavam a água do córrego que abastecia o lago artificial e, por isso, ele não ficava 
plenamente cheio nos finais de semana. A fim de comprovar essa situação, buscamos conversar com alguns caminhoneiros como isso acontecia e um deles mostrou o local e explicou o funcionamento do conflito.

Existe um ponto de captação d'água adaptado para encher os caminhões-pipa que se origina de uma separação do leito do córrego através de uma linha de pedras (Figura 8). Dessa maneira, o canal que leva água diretamente para as piscinas dos balneários foi dividido em dois cursos (Figura 9) que atendem interesses divergentes do ponto de vista do uso.

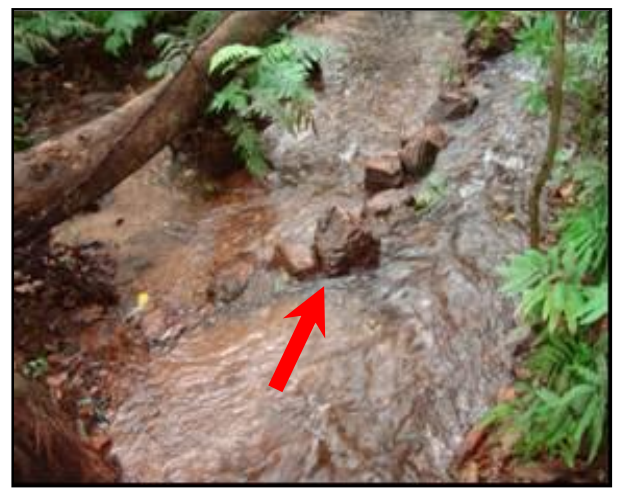

Figura 8. "Divisão das águas"

Autor: Costa, E.A., 2007

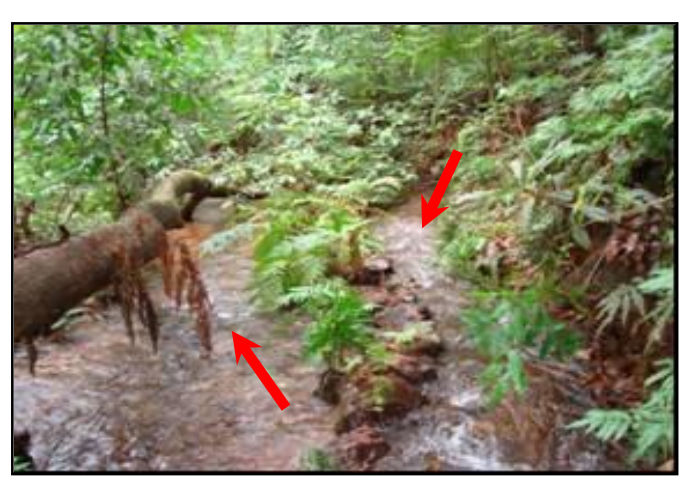

Figura 9. Os dois cursos d'água gerados Autor: Costa, E.A., 2007

Sendo assim, nos meses de seca (especialmente entre abril e outubro), quando diminui o fluxo da água fluvial, os caminhoneiros e os funcionários do balneário disputam o deslocamento das pedras para aumentar o volume de água. Como os caminhões demoram muito tempo para abastecer (algumas vezes até noventa minutos) o jeito foi buscar alternativas. Foi possível apurar que os mais antigos caminhoneiros ensinaram aos mais novos "os caminhos das pedras", literalmente conforme apontado na figura 8. Geralmente, durante a noite para evitar represálias dos proprietários da área, os caminhoneiros entram sorrateiramente na mata e mudam a posição das pedras do córrego de modo a permitir a passagem de uma maior quantidade de água na direção do ponto de abastecimento. Outra vantagem dessa artimanha é que os funcionários ou o proprietário do balneário só irão perceber a diminuição do fluxo d'água no dia seguinte, garantindo mais tempo de uso de maior 
quantidade de água. Dessa forma, a água escoa mais abundantemente pelo leito construído artificialmente considerando a declividade, que atravessa a estrada através de um sistema de tubulação, e volta a percorrer um trecho de 50 metros a céu aberto para terminar num cano estrategicamente colocado, que permite enchimento dos caminhões (Figura 10).

Outro aspecto do conflito pelas águas é registrado nos finais de semana entre os banhistas (Figura 11) e os caminhões-pipa. A água que sai do cano adaptado para encher os caminhões é um atrativo à parte e os banhistas procuram tomar a "ducha" para "curar a ressaca", conforme contaram em conversas amistosas. Como os caminhoneiros precisam carregar, para continuar o trabalho, pressionam os banhistas para sair do local, chegando algumas vezes a provocar deliberadamente acidentes, conforme relatos no local.

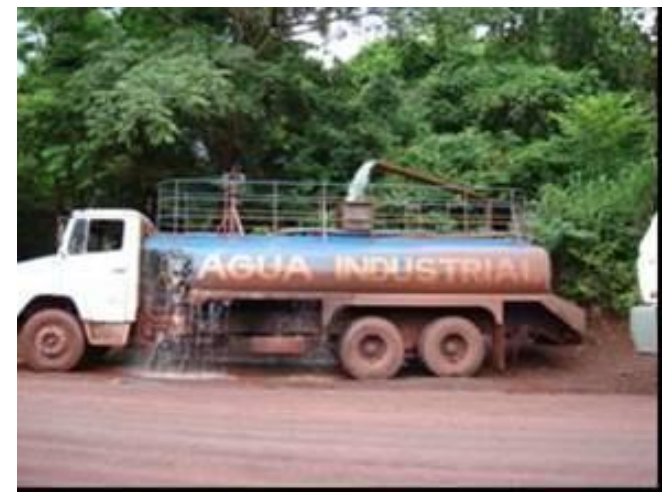

Figura 10. Caminhão pipa enchendo

Autor: Costa, E.A., 2007

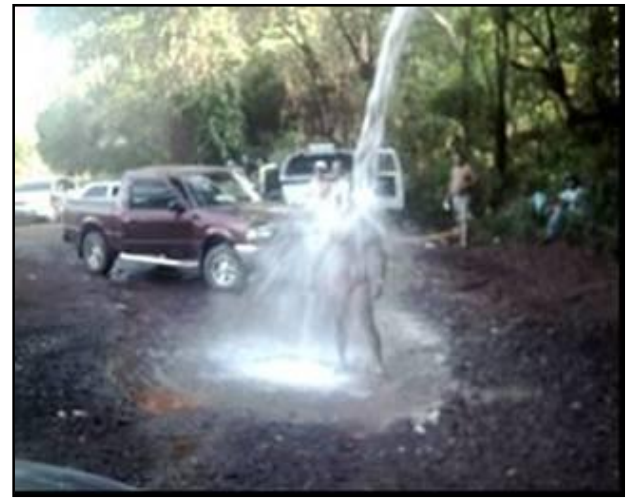

Figura 11. Banhistas no final de semana Autor: Costa, E.A., 2007

Evidentemente essa água utilizada pelos caminhões-pipa não volta para o córrego e consequentemente provoca uma diminuição em cadeia na direção jusante do mesmo. As pessoas que vivem há muito tempo no local afirmam que os cursos fluviais que abastecem os balneários diminuíram $40 \%$ e, além disso, apontam para outros problemas decorrentes das atividades mineradoras: o efeito da poeira na vegetação (Figura 12) e o acúmulo nos leitos fluviais (Figura 13). 


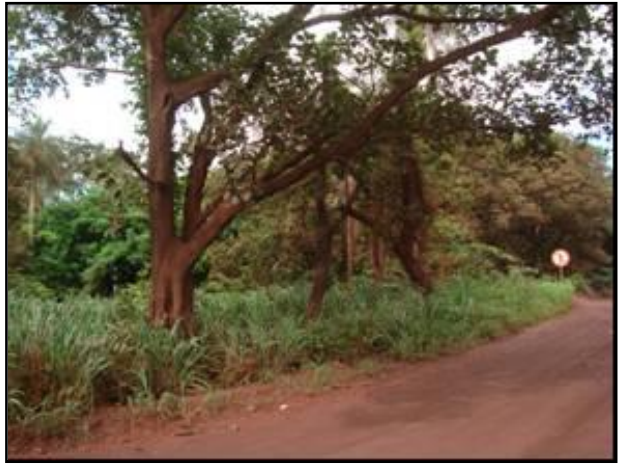

Figura 12. Marcas de ferro na vegetação Autor: Costa, E.A., 2009

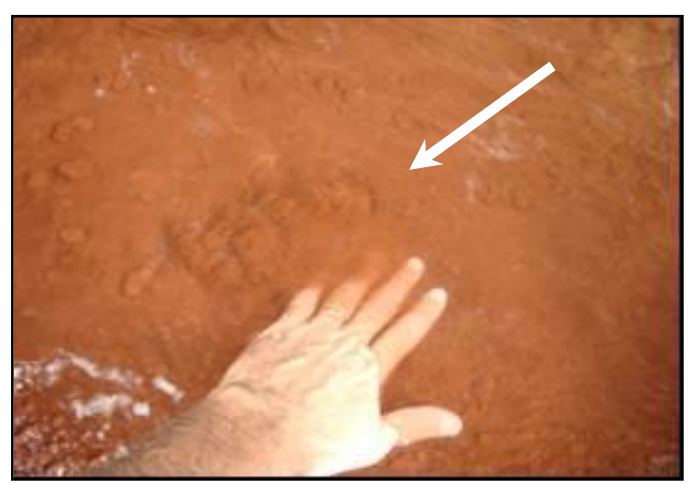

Figura 13. Marcas de ferro na água Autor: Costa, E.A., 2009

A figura 12 indica a necessidade de molhar constantemente as estradas, pois a poeira atinge com muito rigor as espécies vegetais, cujos efeitos ainda não foram estudados no local. De acordo com as impressões dos moradores locais, a própria construção das estradas colabora para o carreamento de sedimentos oriundos da poeira misturada com minério de ferro ao deixar "saídas" para as águas pluviais sem um sistema deposicional. Dessa forma, as águas das chuvas ou os excedentes das aplicações dos caminhões-pipa são conduzidos pela declividade para os leitos fluviais, produzindo uma cor vermelha no fundo. Esse acúmulo é notado facilmente ao mexer com as águas, como demonstrado pela seta na figura 13.

\section{Reflexões finais}

Este olhar para a região de Maria Coelho permitiu a confirmação de que o capital não tem apego às raízes que ele mesmo impulsiona no território, desterritorializando em momentos de risco da diminuição dos ganhos numa localidade e reterritorializando em outras, com melhores perspectivas de lucros. Ficou evidenciada a dinamicidade com que se operam os limites dos territórios e sua capacidade de ser construído e desconstruído, de ampliar e de diminuir suas áreas. 
Verificou-se que as territorialidades individuais mais fragilizadas do ponto de vista político-econômico, quando colocadas num contexto de tensão com agentes territoriais mais poderosos, são mais passíveis de expulsão e reconstrução sob a forma de novas territorialidades em outros locais. Entretanto, não foram colhidas apenas certezas nesta pesquisa. Apareceram alguns questionamentos sem respostas que devem suscitar outras reflexões. Por exemplo, até que ponto o sentimento de topofilia prende uma pessoa num território? Será esse sentimento inversamente proporcional à insegurança da posse? Ou ainda: seria o chão, no sentido de apropriação e dominação, o principal motivador da topofilia e sua parcialidade ou fragilidade produziria uma pseudotopofilia?

Todos os entrevistados moravam a mais de 10 anos na região de Maria Coelho e igualmente todos disseram que amavam o lugar em que estavam e que se pudessem escolher jamais sairiam dali. Contudo, a oposição demonstrada pela maioria não foi capaz de produzir uma vigorosa resistência. A própria criação de uma associação não teve vigor para unir as lutas individuais numa ação coletiva.

Cabe refletir qual modelo de desenvolvimento se deseja produzir. Será possível respeitar as populações tradicionais ao decidirem sobre a exploração de minérios ou sobre a localização de núcleos, distritos e polos industriais? Em Maria Coelho, além dos interesses dos povos tradicionais e dos moradores antigos, confrontados com os desejos das empresas mineradoras, estão as possibilidades de lazer de parte da população urbana dos municípios brasileiros e bolivianos dessa fronteira. Sobram dúvidas e carecem de mais experimentações sobre essas questões.

Por fim, acredita-se que a "geografia de denúncias", debatida sob a luz das categorias de análise da Geografia possui um grande potencial para despertar para questões sociais por detrás do discurso do desenvolvimento. É preciso dar eco aos gritos dos povos tradicionais abafados pelas florestas ou silenciados pelos barulhos das máquinas do desenvolvimento. Igualmente, é preciso buscar respostas para possibilidades verdadeiramente sustentáveis. Os conflitos pelos diversos usos do território entre os atores externos e os atores locais, também são observados em outros pontos do planeta, não apenas em área de mineração, mas, sobretudo, em ambientes onde se instalam empreendimentos que demandam grandes espaços, transformados em seus territórios. 
CONFLITO PELAS TERRAS E PELAS ÁGUAS: NOTAS DAS RELAÇÕES ENTRE MINERADORAS E PROPRIETÁRIOS RURAIS EM CORUMBÁ

Resumo: O discurso do desenvolvimento encobre, por vezes, os conflitos entre as empresas e as populações locais. Este artigo procurou vislumbrar essas situações na região de Maria Coelho, em Corumbá-MS, tendo como contendedores empresas mineradoras e produtores rurais.

Palavras-chave: Corumbá-MS; mineração; conflitos

CONFLICT BY LAND AND BY WATER: NOTES OF RELATIONS BETWEEN MINING ENTERPRISES AND RURAL OWNERS IN CORUMBÁ

Abstract: The development speech may, sometimes, hide the conflicts between enterprises and local population. This article aims to discern indistinctly those situations at Maria Coelho's region, in Corumbá-MS, having mining enterprises and rural landholders as their contenders.

Key-words: Corumbá-MS; mining; conflicts.

\section{BIBLIOGRAFIA}

BRASIL. A Lei No 6.634, de 2 de maio de 1979.m (1979). Dispõe sobre a Faixa de Fronteira, altera o Decreto-lei $\mathrm{n}^{\circ} 1.135$, de 3 de dezembro de 1970. Brasília: Planalto.

CORRÊA, V.B. (2007). Minas do Urucum: as veias abertas de Corumbá. Jornal da Cidade. Campo Grande, MS, 23/dez/2007. Disponível em: http://www.jornaldacidadeonline.com.br. Acesso em: 05 jan.2008.

COSTA, E.A. (2009). Ordenamento territorial em áreas de fronteira. In. Seminário de Estudos Fronteiriços. COSTA, E.A.; OLIVEIRA, M.A.M. (Orgs.). Campo Grande: Editora da UFMS, p. 61-78.

CAMPOS, T.S. (1995). Os recursos minerais do Morro de Urucum e o desenvolvimento regional. Campinas, SP: Unicamp. 
HAESBAERT, R.; LIMONAD, E.(2007). O território em tempos de globalização. In: Revista etc..., espaço, tempo e crítica - Revista Eletrônica de Ciências Sociais Aplicadas. v. 1, n. 2. p.39-52.

HARALYI, N.L.; WALDE, D.H.G. (1986). Os minérios de ferro e manganês da região de Urucum, Corumbá, Mato Grosso do Sul. In. Brasil. Ministério das Minas e Energia. Departamento Nacional de Produção Mineral. Companhia Vale do Rio Doce. Principais depósitos minerais do Brasil, v II, p. 127-144. Brasília: DNPM.

LAMOSO, L.P. (2001). A exploração de minério de ferro no Brasil e no Mato Grosso do Sul. São Paulo: USP. 309 f. Tese. Doutorado em Geografia.

LIMA. (2008). Avaliação Ambiental Estratégica (AAE) do polo mineroindustrial de Corumbá. Rio de Janeiro: LIMA/COPPE/UFRJ.

MCR. (2007). Avaliação Ambiental Estratégica do complexo minerosiderúrgico de Corumbá. São Paulo: Mineração Corumbaense Reunida \& JPG Consultoria e Participações Ltda. 338p.

MOTA, A.C.F.V.(2009). Polos minero-siderúrgicos no Brasil: a contribuição da Avaliação Ambiental Estratégica no caso de Corumbá. Rio de Janeiro: UFRJ/COPPE. 149 f. Dissertação. Mestrado em Planejamento Energético.

SAQUET, M.A.(2007). Abordagens e concepções sobre o território. São Paulo: Expressão Popular.

SOUZA, M.J.L. (2000). O território: sobre espaço e poder, autonomia e desenvolvimento. In CASTRO, I.E.; GOMES, P.C.C.; CORRÊA, R.L. (orgs.). Geografia: conceitos e temas. 2.ed. Rio de Janeiro: Bertrand Brasil, p. $77-116$.

Data de submissão: 16/05/2012

Data de aprovação: 13/07/2013 